\title{
Monitoring the instrument response of the high-sensitivity seismograph network in Japan (Hi-net): effects of response changes on seismic interferometry analysis
}

\author{
Tomotake Ueno ${ }^{1 *}$, Tatsuhiko Saito ${ }^{1}$, Katsuhiko Shiomi ${ }^{1}$ and Yoshikatsu Haryu ${ }^{2}$
}

\begin{abstract}
More than 10 years have passed since observations began to be recorded by Hi-net, a network of high-sensitivity seismometers located in Japan. Several large earthquakes, including the 2011 Tohoku-Oki earthquake, have been recorded by the network during this period. Age-related degradation and the strong ground motion of large earthquakes may change the instrument response of the high-sensitivity seismometers of Hi-net. Thus, we checked the natural frequency $f$ and damping constant $h$ for each Hi-net sensor and monitored the instrument response for 10 years from 2003 to 2013. Most of the sensors showed a stable instrument response over this period. More than $95 \%$ of the sensors whose responses we could well estimate showed small fluctuations in their natural frequencies and damping constants of within $0.05 \mathrm{~Hz}$ and 0.05 , respectively. We also found that many Hi-net sensors in northeastern Japan showed slight changes in the instrument response as a result of the 2011 Tohoku-Oki earthquake. Based on the assumption that the instrument responses remained unchanged, the fractional velocity reduction in the subsurface structure was reported by seismic interferometry analysis. To investigate how changes in the instrument response can cause errors in seismic interferometry analysis, we conducted a synthetic test. The results indicate that the instrument response did not result in systematic variation in the time delay observed in the interferometry analysis. This confirmed that the velocity decrease observed as a result of the 2011 Tohoku-Oki earthquake was not due to artificial instrument error.
\end{abstract}

Keywords: Hi-net sensor; Test coil; Instrument response; Seismic interferometry

\section{Background}

The National Research Institute for Earth Science and Disaster Prevention (NIED) has operated three nationwide seismic networks since the 1990s. The networks consist of approximately 80 broadband seismographs, 1700 strong-motion seismographs, and 800 high-sensitivity seismographs and are referred to as F-net, KiK-net/KNET, and Hi-net, respectively. These three seismic networks observe seismic motions for short to long periods and detect earthquakes of small to large magnitudes (Okada et al. 2004).

\footnotetext{
* Correspondence: ueno@bosai.go.jp

${ }^{1}$ National Research Institute for Earth Science and Disaster Prevention, 3-1 Tennodai, Tsukuba-shi, Ibaraki 305-0006, Japan

Full list of author information is available at the end of the article
}

Hi-net is designed for the detection of small earthquakes and very weak signals from the deep crust. At a Hi-net station, a sensor characterized by a natural frequency of $1 \mathrm{~Hz}$ is installed at the bottom of a borehole of $100 \mathrm{~m}$ or more in depth to reduce background noise (Obara et al. 2005). The performance and limitations of the sensor dynamic range were investigated by Shiomi et al. (2005). The sensor orientation at the bottom of the borehole cannot be observed by the naked eye but may be accurately estimated by analyzing the long-wavelength waveforms and ambient seismic signals (Shiomi 2013). The Hi-net records have been used to determine the accurate hypocenter locations and mechanisms of small earthquakes (e.g., Yukutake et al. 2008) and have contributed to the new finding of a non-volcanic seismic tremor in southwestern Japan (Obara 2002). Additionally, the records have been 
used for the construction of subsurface structure models by seismic travel-time tomography (e.g., Matsubara et al. 2009), receiver function analysis (e.g., Shiomi et al. 2004; Ueno et al. 2008), and scattering-wave analysis (e.g., Takahashi et al. 2009). Although the Hi-net sensors were originally designed for regional or small earthquakes, high-quality observations can be successfully achieved using a simulation filter from the Hi-net sensors to the F-net broadband sensors for far-field large earthquakes (Maeda et al. 2011). The waveforms recorded by the Hi-net stations are available on the NIED Hi-net website (http://www.hinet.bosai.go.jp/?LANG=en).

Wegler and Sens-Schönfelder (2007) proposed a method referred to as passive image interferometry (PII), in which fractional changes in the background seismic velocity structure (less than approximately $1 \%$ ) can be identified by monitoring a correlation function of the ambient seismic noise. This method has successfully detected temporal changes in the subsurface structure associated with a large earthquake (e.g., Brenguier et al. 2008a), a volcanic eruption (e.g., Brenguier et al. 2008b), and Earth tides (Takano et al. 2014). Since Hi-net provides continuous high-quality seismograms, Hi-net records are suitable for the PII. For example, the PII of the Hi-net records revealed a significant velocity decrease of more than $0.3 \%$ for the $2004 \mathrm{Mw} 6.6$ mid-Niigata earthquake (Wegler et al. 2009), the $2007 \mathrm{Mw}$ 6.6 Noto Hanto earthquake (Ohmi et al. 2008), and the seismic swarm activity by magma intrusions in the Izu Peninsula, Japan (Ueno et al. 2012). Additionally, for the 2011 Tohoku-Oki earthquake, a significant velocity decrease of approximately $1.5 \%$ was reported based on monitoring by the autocorrelation function (ACF) using Hi-net records (Minato et al. 2012).

These PII results implicitly presumed stable instrument responses of the Hi-net sensors during the analysis period. However, stability is not always assured, because some sensors suffer from ground motions larger than the stroke limitation. This can damage the sensor and change the instrument response. Figure 1 shows records of the 2011 Tohoku-Oki earthquake at the N.KMIH station. The KiKnet waveform indicates strong motions larger than the stroke limitation of the Hi-net sensor which is $2 \mathrm{~mm}$ (Fig. 1b). Thus, although it appears to work correctly, the Hi-net sensor cannot accurately record large ground motions, because of the stroke limitation (Fig. 1c). Such large signals may cause significant changes in the instrument response for PII because PII is sensitive to very small velocity structure changes (approximately $1 \%$ ). To maintain a satisfactorily high performance of a seismograph and guarantee accurate PII results, it is necessary to carefully monitor the changes in the instrument response and examine the effects of these changes on the PII.

This study thoroughly investigates the instrument responses of approximately $800 \mathrm{Hi}$-net sensors using a daily test coil signal over a period of 10 years that includes the 2011 Tohoku-Oki earthquake. Analyzing the test coil signal, we estimated the natural frequency and damping constant as the instrument responses for each sensor of Hi-net. Additionally, we examined how changes in the instrument response can affect the subsurface structure changes detected by PII for the 2011 Tohoku-Oki earthquake.

\section{Methods}

\section{Evaluation of instrument response}

We estimated the natural frequency $f$ and damping constant $h$ for each Hi-net sensor by using a daily test signal. Figure 2a shows a schematic of a Hi-net seismometer. A coil bobbin, which works as a pendulum in the seismometer, includes a signal coil and a test coil. The signal coil is for the detection of ground motion, which induces a current in the coil. The coil bobbin is displaced by an electrical voltage applied to the test coil. When we apply a voltage $e_{i}$ to a test coil with length $l$ and resistance $R$ in a magnetic flux density $B$, the weight of the coil bobbin $M$, the generated Lorentz force per unit mass $f$, given by

$$
f=\frac{B l}{M R} e_{i}
$$

displaces the coil bobbin in the vertical direction. The values of $B, l, M$, and $R$ are constant. When an electrical voltage is applied suddenly as shown in Fig. $2 \mathrm{~b}$, the force is produced in a stepwise shape. The equation of motion for the coil bobbin is then given by

$$
\ddot{z}(t)+2 h \omega_{0} \dot{z}(t)+\omega_{0}^{2} z(t)=f H(t)
$$

where $z(t)$ is the displacement of the bobbin, $\omega_{0}$ is the natural angular frequency, $h$ is the damping resistance, and a function $H(t)$ is defined as

$$
H(t)= \begin{cases}0, & t<0 \\ 1, & t \geq 0\end{cases}
$$

We then obtained $Z(\omega)$ from the Fourier transform of $z(t)$ as

$$
Z(\omega)=\frac{C_{0}}{\left(\omega^{2}-2 h \omega_{0} i \omega-\omega_{0}^{2}\right) i \omega},
$$

where $C_{0}$ is a constant which includes the constant values of $B, l, M$, and $R$. Equation (3) shows the displacement spectrum of the coil bobbin. The displacement of the coil bobbin induces the voltage $e_{0}$ in the signal coil. The output voltage $e_{0}$ produce by this bobbin motion is proportional to the velocity of the coil bobbin $v(t)=\mathrm{d} z(t) / \mathrm{d} t$, and the Fourier transform of the velocity is given by 


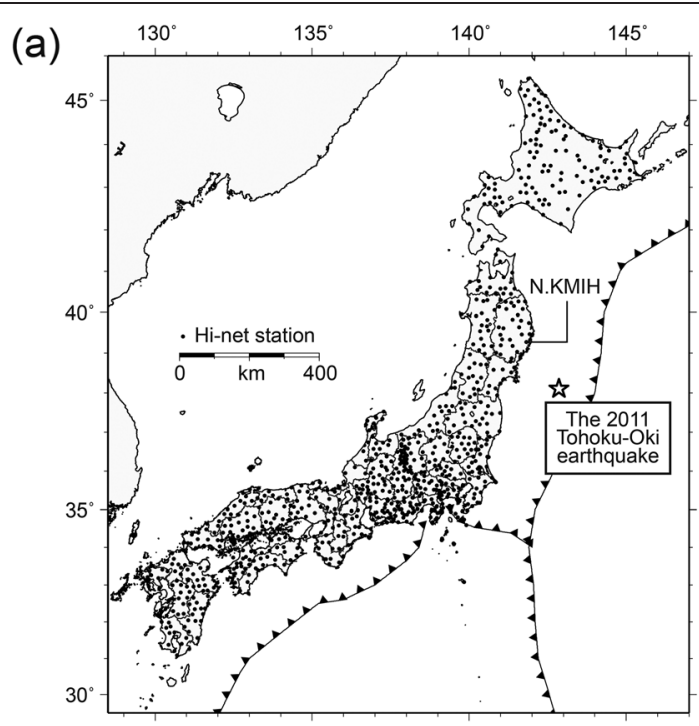

(b)

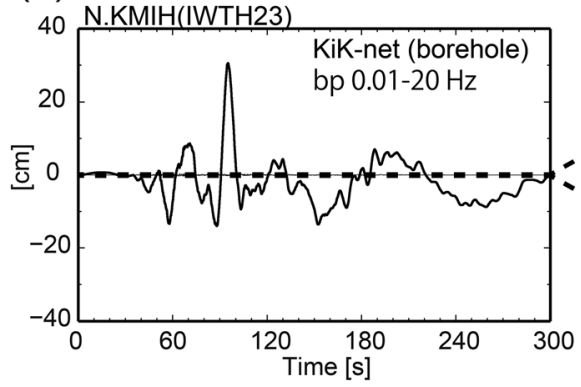

(c)

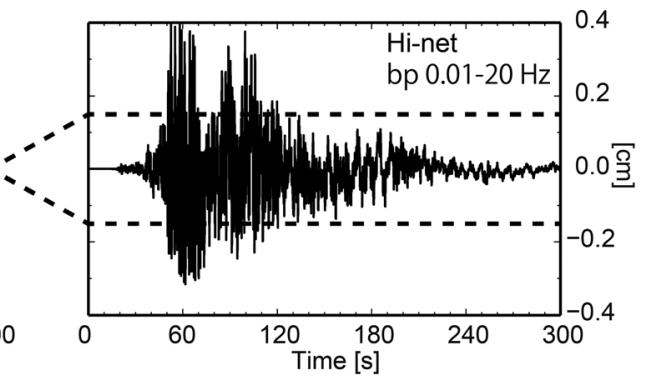

Fig. 1 Epicenter and Hi-net station locations and waveform examples. a Distribution of the NIED Hi-net stations and the epicenter of the 2011 Tohoku-Oki earthquake. Vertical waveforms of the 2011 Tohoku-Oki earthquake recorded at the N.KMIH (IWTH23) station with b the KiK-net borehole acceleration seismometer and $\mathbf{c}$ the Hi-net velocity seismometer. Both seismometers were placed in the same borehole. Band-pass filters of $0.01-20 \mathrm{~Hz}$ were applied to the waveforms, and they were transformed to displacements. The dashed line indicates the reliable stroke width ( $\pm 15 \mathrm{~mm})$ of the Hi-net vertical sensor (Shiomi et al. 2005)

$$
V(\omega)=\frac{C_{0}}{\omega^{2}-2 h \omega_{0} i \omega-\omega_{0}^{2}}
$$

Therefore, we obtain the output voltage, in other words, an instrument response, with respect to the force given by the right-hand side of Eq. (2) by performing the inverse Fourier transform given by Eq. (4).

The electrical voltage was applied every morning at 9:00 AM, as shown in Fig. 2b, and a test signal was obtained for each Hi-net sensor, as shown in Fig. 2c. Figure 3 shows examples of the calculated instrument responses (test signals) for three difference sets of natural frequencies $f$ and damping constants $h:(f, h)=(1.0 \mathrm{~Hz}, 0.7),(0.9 \mathrm{~Hz}$, $0.6)$, and $(0.5 \mathrm{~Hz}, 0.3)$. The standard Hi-net sensor is set to $1.0 \mathrm{~Hz}$ and 0.7 . If the instrument response is characterized by $f=0.9 \mathrm{~Hz}$ and $h=0.6$, the difference from the standard instrument response is not very large, whereas a large difference is recognized for the case of $f=0.5 \mathrm{~Hz}$ and $h=0.3$.
Estimating the parameters of instrument response using a test coil record

We estimated the natural frequency $f$ and damping constant $h$ for the Hi-net sensors using a grid-search method. We calculated the root mean square reduction (rr), which is defined as

$$
\mathrm{rr}=1-\sqrt{\frac{\sum_{i}\left[S\left(t_{i}\right)-O\left(t_{i}\right)\right]^{2}}{\sum_{i}\left[O\left(t_{i}\right)\right]^{2}}},
$$

where $S(t)$ and $O(t)$ are the calculated and observed instrument responses, respectively. The $\mathrm{rr}$ is larger when the equation better reproduces the observation. It takes a maximum value of 1 when the calculation perfectly matches the observation. By changing $f$ from 0.1 to $2.1 \mathrm{~Hz}$ with a step of $0.01 \mathrm{~Hz}$ and $h$ from 0.1 to 2.1 with a step of 0.01 , we investigated an 


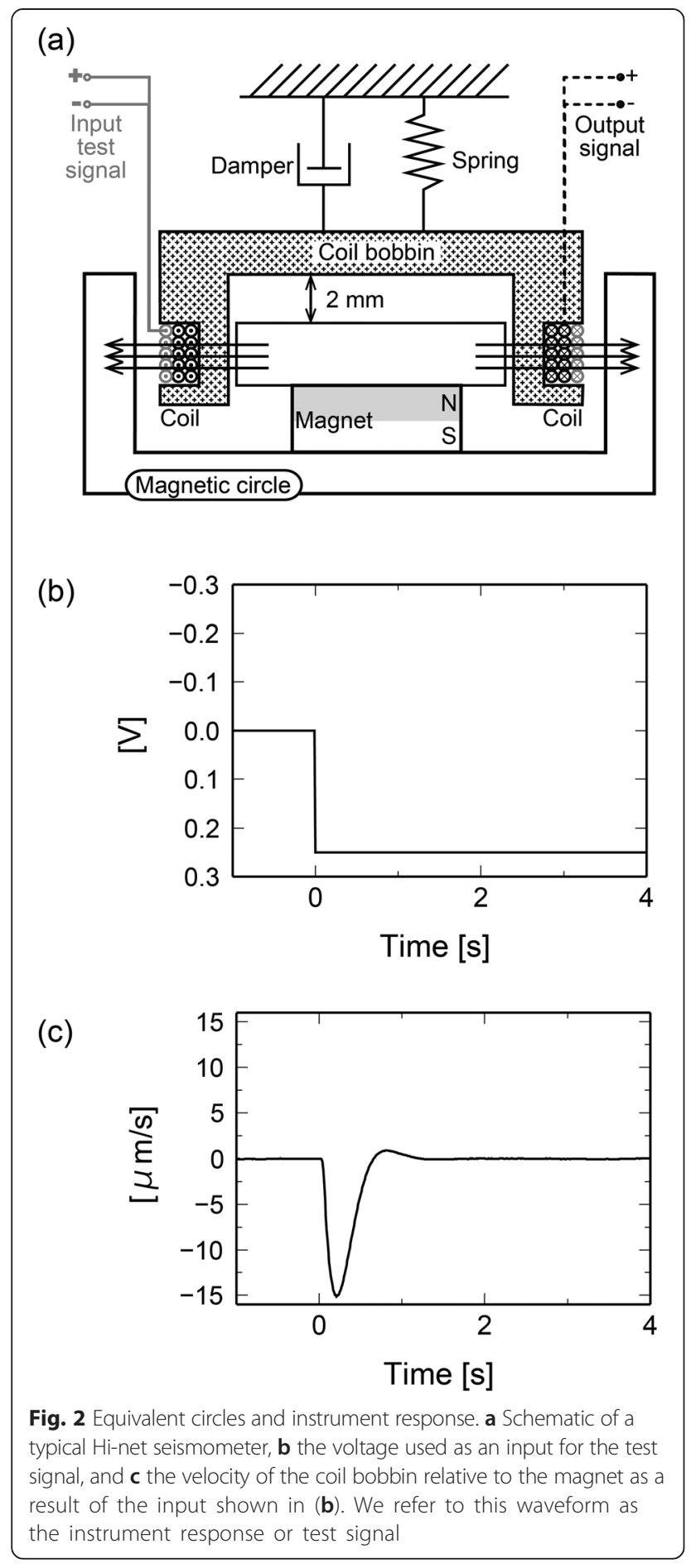

appropriate range of $f$ and $h$ values to maximize the value of rr.

Figure $4 \mathrm{a}$ shows the rr distribution as a function of $f$ and $h$ for the instrument response at the N.KMIH station (the station location is shown in Fig. 1a) recorded on 4 June 2010. The maximum rr value is 0.98 for a parameter set of $f=1.11 \mathrm{~Hz}$ and $h=0.68$. Figure $4 \mathrm{~b}-\mathrm{e}$ compares the observed and calculated

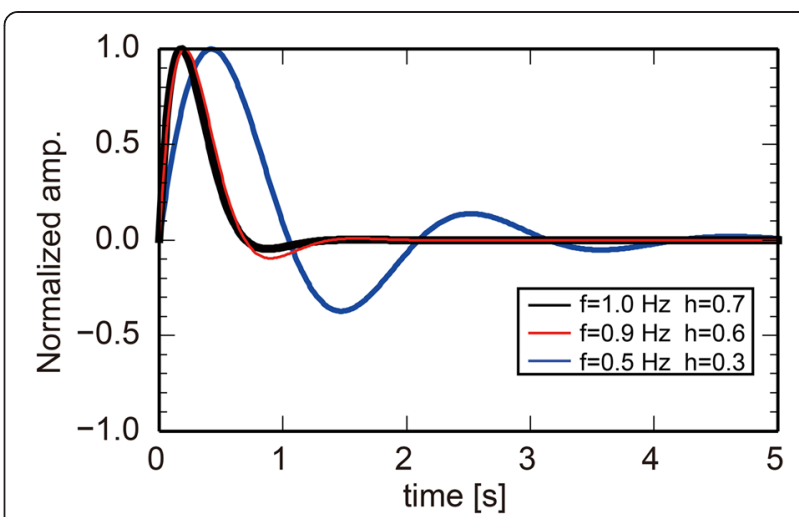

Fig. 3 Examples of calculated instrument responses. Black, red, and blue lines indicate parameters of $(f, h)=(1.0 \mathrm{~Hz}, 0.7),(0.9 \mathrm{~Hz}, 0.6)$, and (0.5 Hz, 0.3), respectively

instrument responses for each $f$ and $h$ set. Very good agreement between the observed and calculated instrument responses is obtained when the rr value is larger than 0.95. This study assumes that the ranges of $f$ and $h$ that yield rr values larger than 0.95 are the estimated natural frequency and damping constant for an instrument response. We estimated these ranges to be $f=1.05-1.15 \mathrm{~Hz}$ and $h=0.6-0.75$ for the instrument response at the N.KMIH station in Fig. 4a.

\section{Results and discussion}

Figure 5 shows an example of the time series of $f, h$, rr, and the root mean square (RMS) amplitude of the waveform from 2003 to 2013 for three component seismographs at the N.KMIH station in the Tohoku region (the station location is shown in Fig. 1a). The rr value is an important index in the stability determination for parameter estimation, as shown in Fig. 4. For the vertical component time series in Fig. 5a, low rr values were estimated occasionally and the values of $f$ and $h$ were not always stable. It was usually because natural earthquakes such as aftershocks of the Iwate-Miyagi Nairiku earthquake (Mw 6.9) in 2008 and the 2011 Tohoku-Oki earthquake ( $\mathrm{Mw}$ 9.1) contaminated the test signals. However, most rr values in the whole period were greater than 0.95 , which indicates very good agreement between the observed and calculated instrument responses. The natural frequencies and damping constants during the analyzed period were estimated to be in the ranges of $f=1.05-1.10 \mathrm{~Hz}$ and $h=$ $0.65-0.75$, respectively. The results of the north-south and east-west components were similar to those of the vertical component, as shown in Fig. 5b, c.

Figure 6 summarizes the distribution of the instrument responses for all Hi-net stations in this study, including a histogram of the average $f$ (Fig. 6(a1)), the standard deviation of $f$ (Fig. 6(a2)), the average $h$ 
(a)

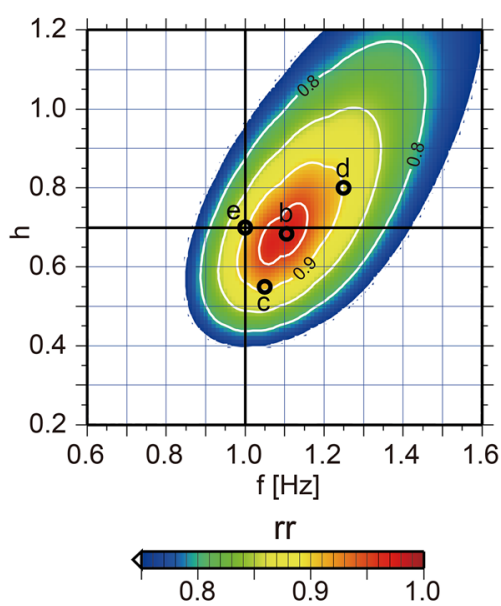

(b)

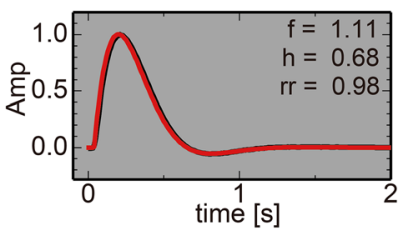

(c)

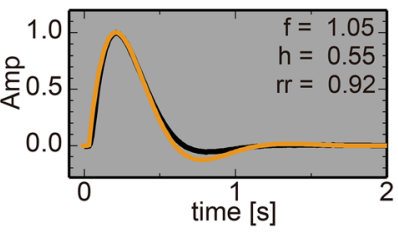

(d)

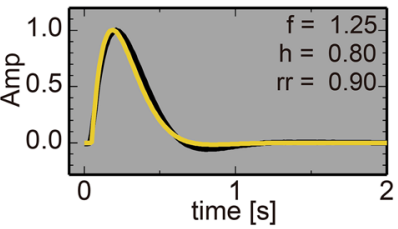

(e)

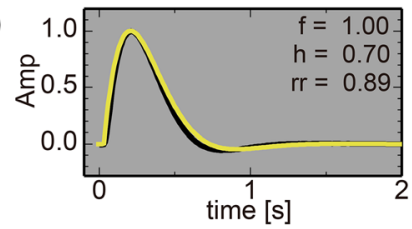

Fig. 4 Results of a grid-search method for the determination of the natural frequency $f$ and damping constant $h$ of a Hi-net sensor. a Values of $\mathrm{rr}$ as a function of $f$ and $h$. b-e Observed (black line) and calculated instrument responses for various parameter sets: (b) $f=1.11 \mathrm{~Hz}$ and $h=0.68, \mathbf{c} f=1.05 \mathrm{~Hz}$ and $h=0.55, \mathbf{d} f=1.25 \mathrm{~Hz}$ and $h=0.80$, and $\mathbf{e} f=1.0 \mathrm{~Hz}$ and $h=0.70$. Each calculated waveform is colored according to the value of $\mathrm{rr}$
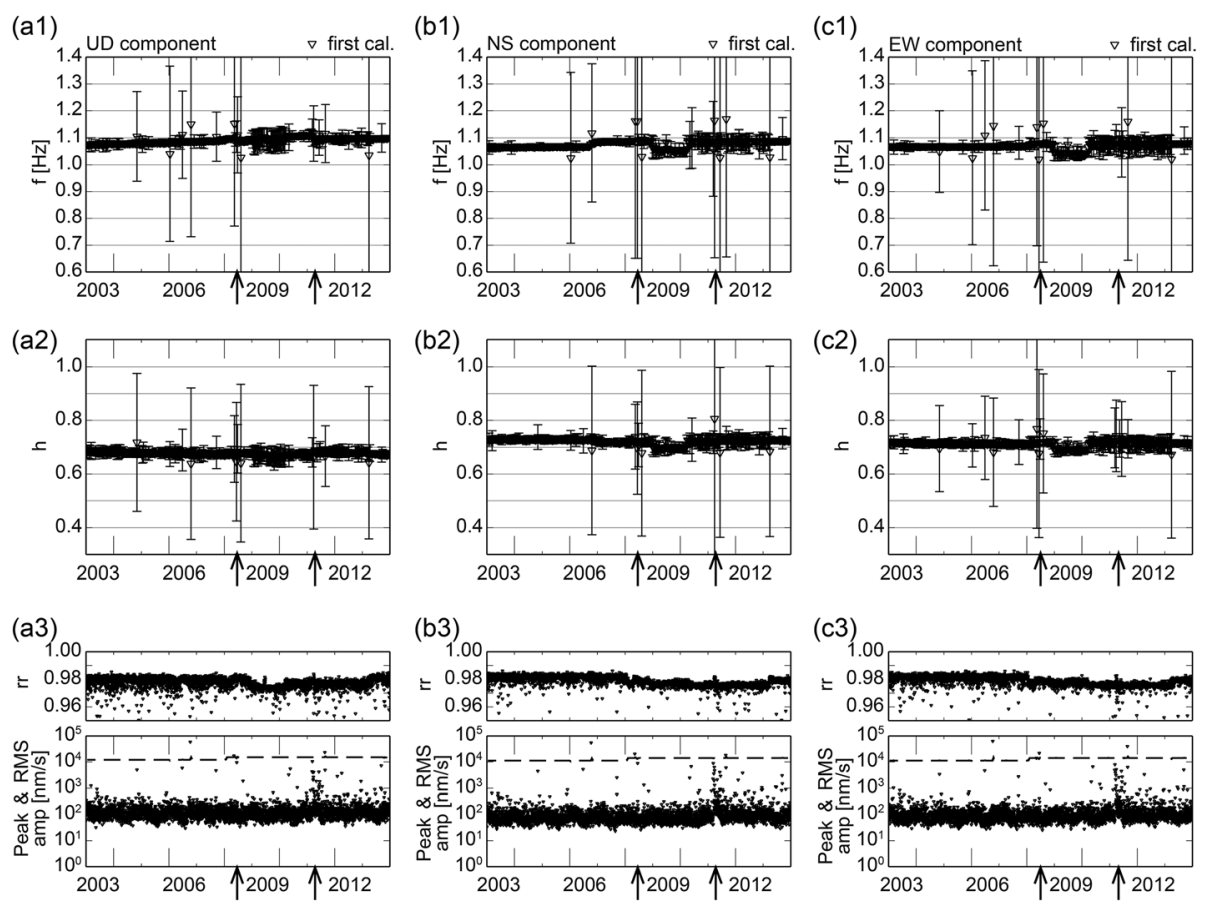

(b3)
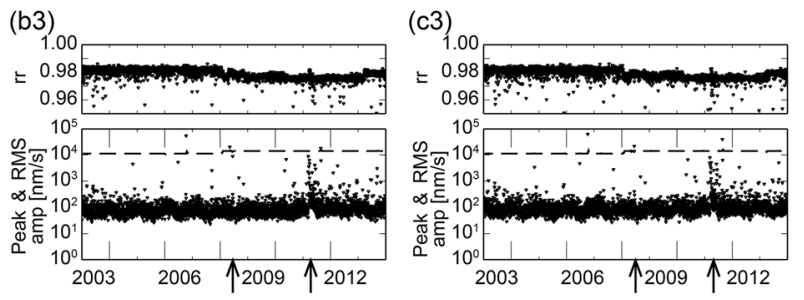

Fig. 5 Temporal changes in the instrumental parameters from 2003 to 2013. a Vertical components of (a1) the natural frequency $f$ Hz of the test signal at the N.KMIH station, (a2) the damping constant $h$, and (a3) the rr and the peak (broken line) and RMS (dot) amplitudes $3 \mathrm{~s}$ before the test signal. b North-south and $\mathbf{c}$ east-west components of the variables in (a). The arrows indicate the dates of the Iwate-Miyagi Nairiku Earthquake in 2008 and the 2011 Tohoku-Oki earthquake 


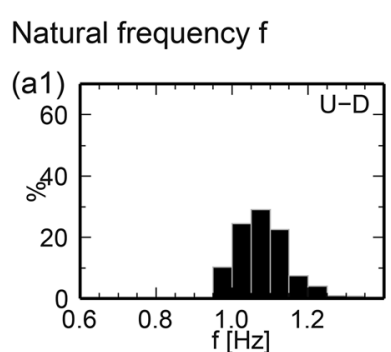

(a2)

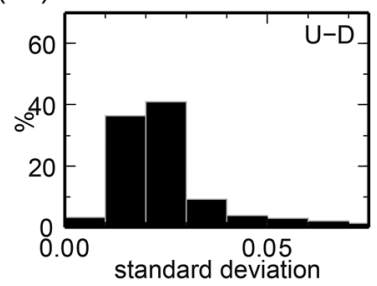

Damping constant $\mathrm{h}$

(a3)
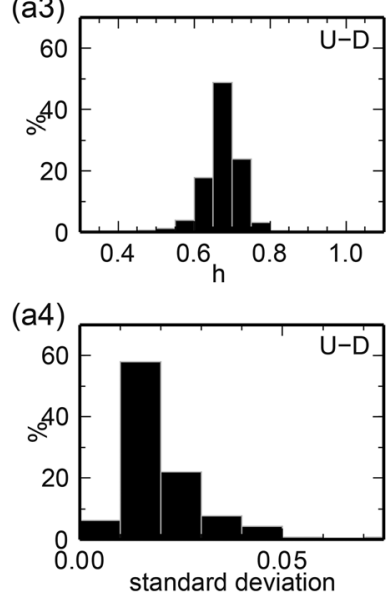

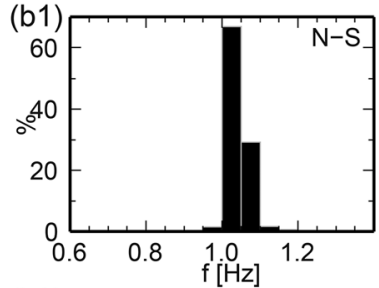

(b2)

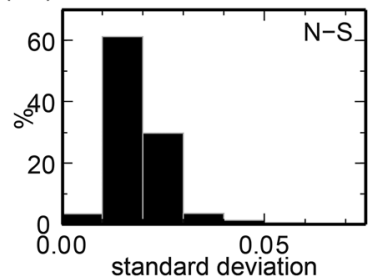

(c2)
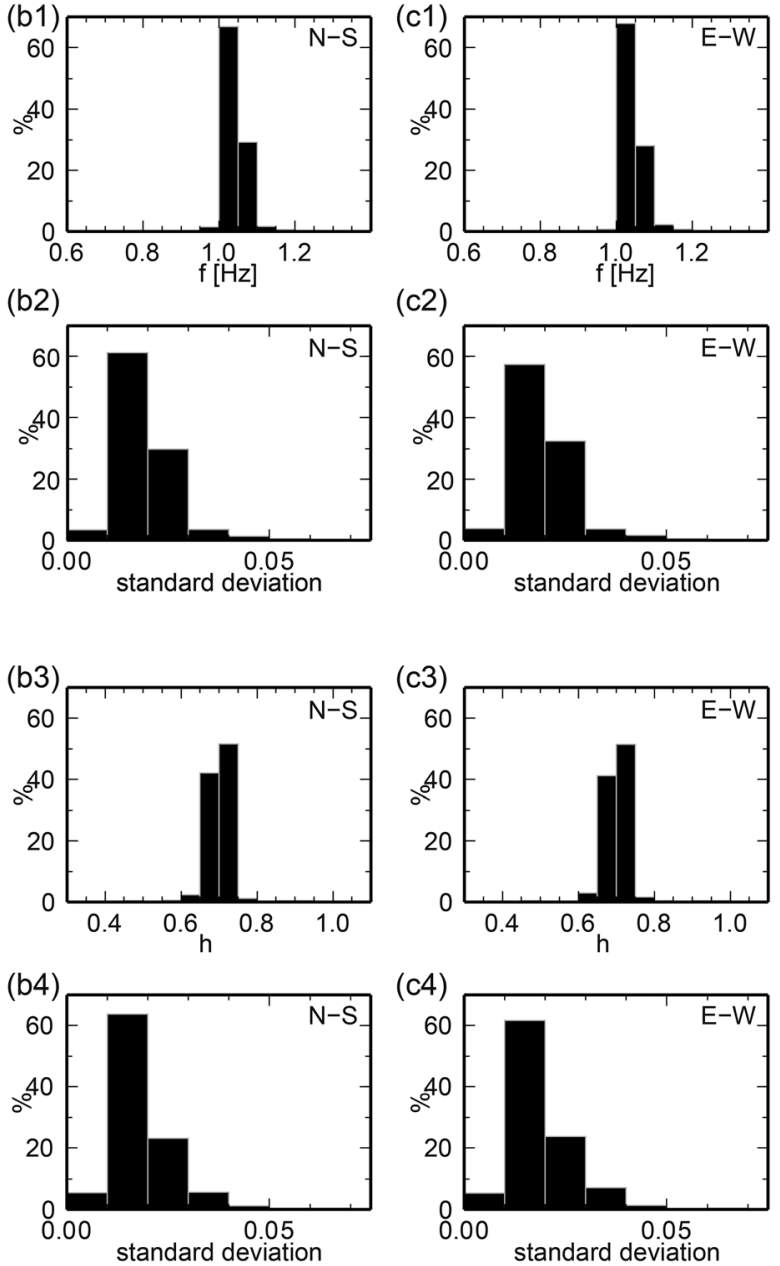

(c3)

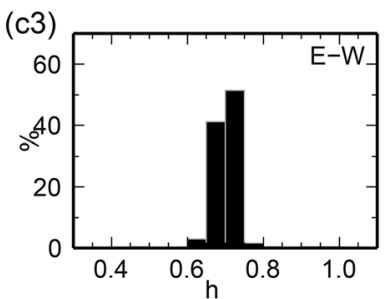

(c4)

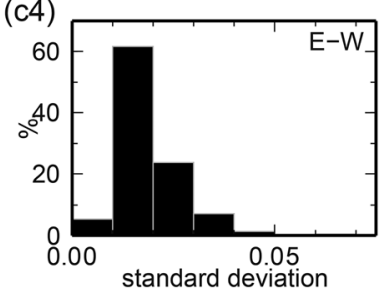

Fig. 6 Histograms of the natural frequency and damping constant distributions. a Distributions of the vertical components of (a $)$ ) the natural frequency $f,(a 2)$ the standard deviation of $f$ over 10 years, (a3) the damping constant $h$, and (a4) the standard deviation of $h$ over 10 years. The values were counted when the value of rr exceeded 0.95. b North-south and $\mathbf{c}$ east-west components of the variables in (a)

(Fig. 6(a3)), and the standard deviation of $h$ (Fig. 6(a4)) for the vertical sensors for over 10 years for each station. Figure $6 \mathrm{~b}, \mathrm{c}$ indicate the same values for the north-south and east-west components of the seismometers, respectively. More than $95 \%$ of the stations have natural frequencies and damping constants in the ranges of $f=1.0-1.2 \mathrm{~Hz}$ and $h=0.6-0.75$. The standard deviations of the $f$ and $h$ for each station are within $0.05 \mathrm{~Hz}$ and 0.05 , respectively, indicating that there is no significant variation in the instrument response (see Fig. 4). Therefore, we conclude that the Hi-net sensors as a whole are well controlled, with small instrument-to-instrument variations. Additionally, the sensors are very stable over the analyzed 10 years, although slight fluctuations in the instrument response were sometimes recognized during large earthquakes.
Influence of changes in instrument response on crustal monitoring by interferometry analysis

Passive image interferometry of the 2011 Tohoku-Oki earthquake

During the 2011 Mw 9.1 Tohoku-Oki earthquake, a large-amplitude seismic wave propagated through eastern Honshu (e.g., Suzuki et al. 2011). Fractional subsurface velocity change after the earthquake was reported associated with the strong motion and the large stress/ strain change (e.g., Brenguier et al. 2014; Nakata and Snieder 2011). We conducted PII using the records of the vertical components of Hi-net. Following a stretching method proposed by Wegler et al. (2009), we estimated the time delay of the ACF from the reference ACF in the lag time of 4-15 s for the frequency range of 1-3 Hz and detected the changes in the subsurface 
seismic velocity structure that occurred during the 2011 Tohoku-Oki earthquake.

Figure 7 shows the ACFs obtained from the continuous Hi-net records of the N.KMIH station during the period of 2008-2013. The ACF, which is considered as a Green's function of the source and receiver located at the station, does not vary significantly and shows high stability over each time period. However, looking carefully, a slight time delay from the lag time can be observed immediately following the occurrence of the 2011 Tohoku-Oki earthquake. For example, there is a time delay of approximately $0.1 \mathrm{~s}$ at a lag time of approximately $8.5 \mathrm{~s}$.

The time delays between the reference ACF and the ACFs from 30 October 2010 and 30 October 2011 at each lag time are estimated in Fig. 8(a1, a2), respectively. The reference ACF is defined as the mean of the ACFs in 2009 and 2010. For comparison, we first estimated the time delay on 30 October 2010, a day without a large

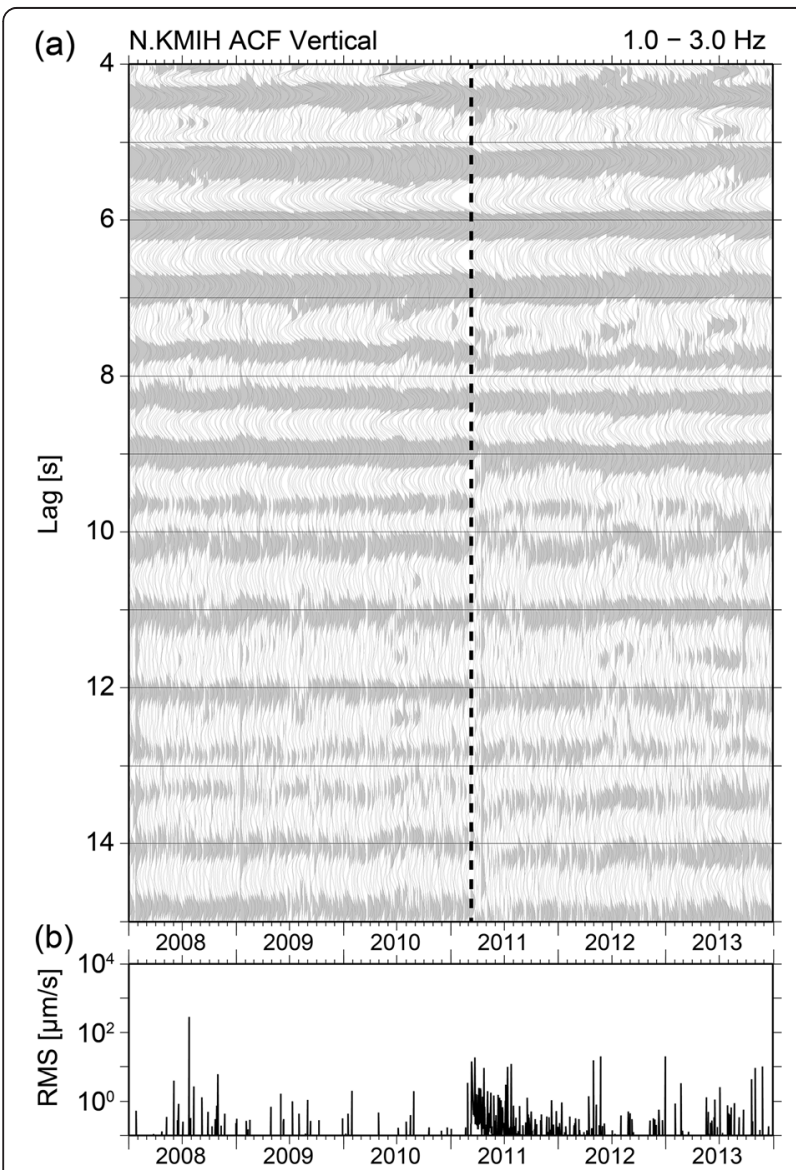

Fig. 7 Autocorrelation functions (ACFs) and noise level. a ACFs of the vertical component for the N.KMIH station. The ACFs were made from band-pass-filtered waveforms (passband $=1-3 \mathrm{~Hz}$ ). The broken line indicates the date of the 2011 Tohoku-Oki earthquake. b Root mean square amplitude of waveforms for the duration of $1 \mathrm{~h}$ after band-pass filtering event, as shown in Fig. 8(a1). No systematic variation of the time delay with the lag time is evident in the figure. Conversely, in Fig. 8(a2), which shows the time delay on 30 October 2011, a day roughly 5 months after the 2011 Tohoku-Oki earthquake, it is evident that the time delay increases with increasing lag time. The stretching method in the PII interprets the time delay of an ACF as being caused by a decrease in the background velocity structure; when the background seismic velocity decreases by $\alpha \%$, the time delay is given by $\mathrm{d} t=\alpha / 100$ for a lag time of $t$ (e.g., Sens-Schönfelder and Wegler 2006). We estimated that the velocity structure decreased by approximately $0.5 \%$ at the N.KMIH station after the 2011 Tohoku-Oki earthquake (Fig. 8b).

\section{Changes in instrument response}

Since the ground shaking caused by the 2011 TohokuOki earthquake was too strong for a high-sensitivity seismograph, an instrument response change must be considered. After the earthquake, in fact, a very small change of the $f$ and the $h$ seems to occur at N.KMIH as shown in Fig. 8c. We may have misidentified the change in the instrument response as corresponding to a change in the subsurface velocity structure resulting from the earthquake. Therefore, we investigate whether the change in the instrument response can misrepresent the subsurface velocity change.

Figure 9 shows the distribution of the differences between the instrument responses before and after the earthquake. We found that many stations in northeastern Japan had small instrument response changes. This means that the instrument responses for the Hi-net sensors, especially those in northeastern Japan, were affected by the large shaking of the 2011 Tohoku-Oki earthquake. However, the changes in the natural frequencies and damping constants for the sensors were smaller than $\pm 0.05 \mathrm{~Hz}$ and \pm 0.05 , respectively.

\section{Apparent temporal changes in subsurface structure due to changes in instrument response}

We then examined the extent to which the change in the instrument response during the 2011 Tohoku-Oki earthquake could affect the velocity change estimated by PII. First, a band-pass filter with a passband of $1-3 \mathrm{~Hz}$ was applied to ambient noise recorded by a broadband F-net station (N.KSNF) as shown in Fig. 10a. We then convoluted instrument responses characterized by $(f, h)=(1.0 \mathrm{~Hz}, 0.7),(0.9 \mathrm{~Hz}, 0.6)$, and $(0.5 \mathrm{~Hz}, 0.3)$ to simulate a seismogram of a normal Hi-net sensor, a seismogram of a Hi-net sensor which was slightly damaged by age-related degradation or large earthquakes, and a seismogram in an extreme case, respectively (black, red, and blue lines, respectively, in Fig. 10b). Figure 10c shows the ACFs for the three types of simulated 

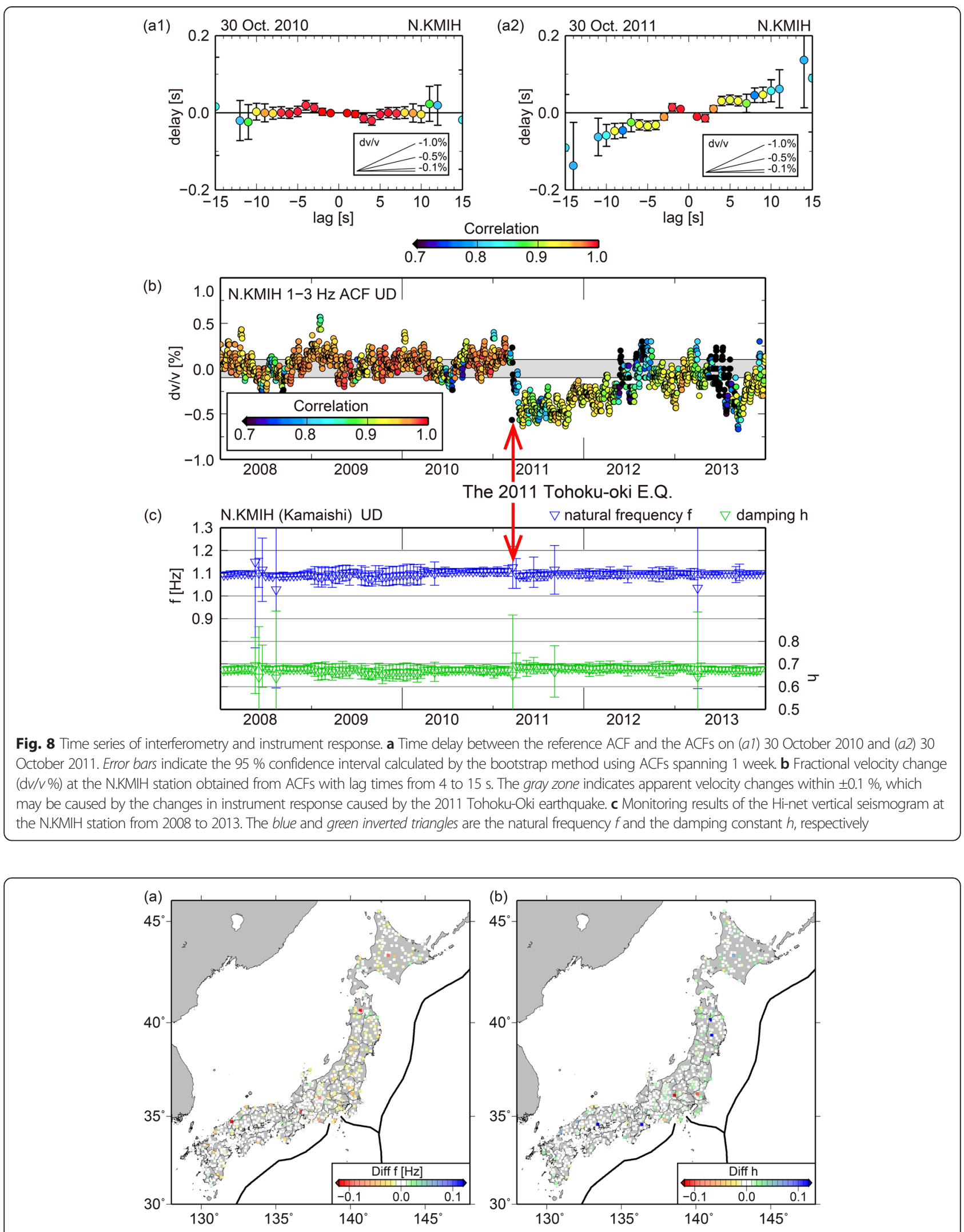

Fig. 9 Spatial distributions of the temporal changes in the instrument response. a Spatial distribution of the difference between the estimated a natural frequencies $f$ and $\mathbf{b}$ damping constants $h$ before and after the 2011 Tohoku-Oki earthquake 

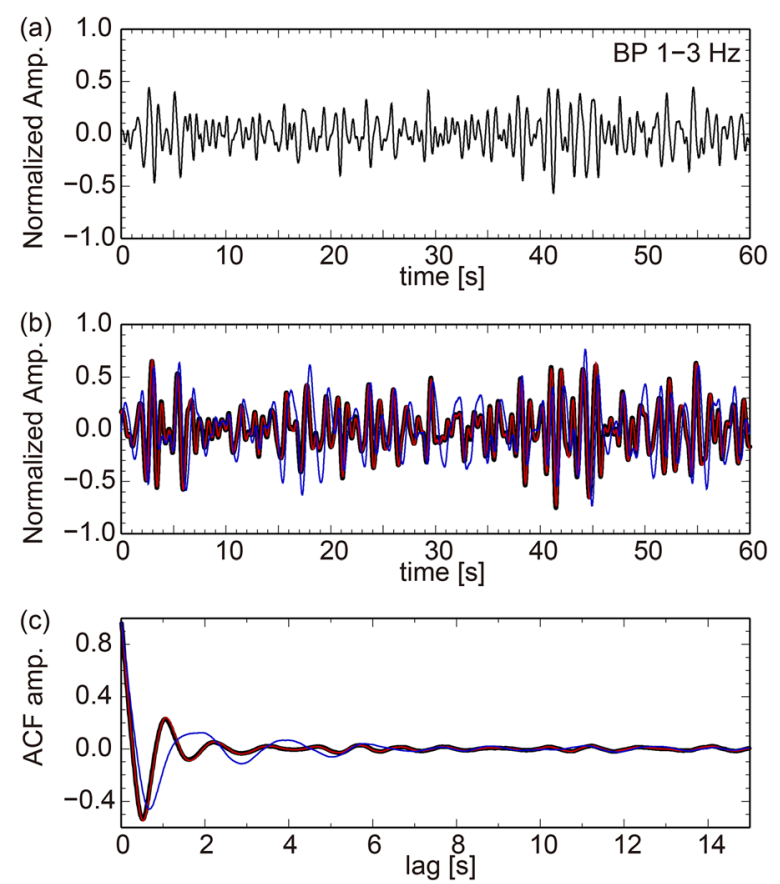

Fig. 10 Examples of an apparent velocity change test. a An observed F-net record. $\mathbf{b}$ Simulated Hi-net waveforms, which are made by convoluting three types of instrument responses with parameters of $f=1 \mathrm{~Hz}$ and $h=0.7$ (black line), $f=0.9 \mathrm{~Hz}$ and $h=0.6$ (red), and $f=0.5 \mathrm{~Hz}$ and $h=0.3$ (b/ue). c ACFs of the simulated Hi-net waveforms shown in (b)

seismogram records which were calculated using the same method as in Fig. 4.

Figure 11 shows the estimated time delay from the reference ACF with $f=1.0 \mathrm{~Hz}$ and $h=0.7$ for each lag time of ACFs with $f=0.9 \mathrm{~Hz}$ and $h=0.6$, which represents a possible change in the instrument responses after the 2011 Tohoku-Oki earthquake, and $f=0.5 \mathrm{~Hz}$ and $h=0.3$, which represents an unrealistically extreme case. We did not find a systematic time delay according to the change in the lag time. Additionally, a very small velocity change of less than $0.1 \%$ may be obtained by the stretching method when a possible response change occurs (Fig. 11a). However, the velocity reduction caused by the 2011 Tohoku-Oki earthquake was $0.5 \%$, as shown in Fig. 8(a2) and 8b. Since this velocity change is significantly larger than $0.1 \%$, the obtained velocity structure change is not an artifact caused by the instrument response change during the large earthquake. Figure 11b shows the result for an extremely large instrument response change, which shows unstable values of the lag time $\mathrm{d} t$ at each elapsed time. This extreme case of changes in the instrument response cannot reproduce a systematic change in the lag time, according to the lag time obtained by the PII (Fig. 8(a2)). Therefore, we conclude that the change of an instrument response caused by age-related degradation or large earthquakes is usually too small to affect the result of the PII.

\section{Conclusions}

We monitored the instrument responses for Hi-net sensors for 10 years from 2003 to 2013 by estimating their natural frequencies $f$ and damping constants $h$ from the test signal. We found that the Hi-net sensors are well controlled with small instrument-to-instrument variation; more than $95 \%$ of the sensors show natural frequencies in the range of $f=1.0-1.2 \mathrm{~Hz}$ and damping constants in the range of $h=0.6-0.8$. Furthermore, each $\mathrm{Hi}$-net sensor is very stable against the temporal change over a decade. Their standard deviations of the natural frequency and damping constant were within $0.05 \mathrm{~Hz}$ and 0.05 , respectively. During the 2011 Tohoku-Oki earthquake, large seismic waves exceeding the dynamic range of the Hi-net sensor were observed at the stations near the earthquake focal area. Small changes in the instrument response were also recognized in the $\mathrm{Hi}$-net sensors after the earthquake. Thus, we conducted a synthetic test to investigate how changes in the instrument response can cause errors in seismic interferometry analysis. The test indicated that the instrument response change did not result in systematic variation in the time delay obtained from the PII of the 2011 Tohoku-Oki
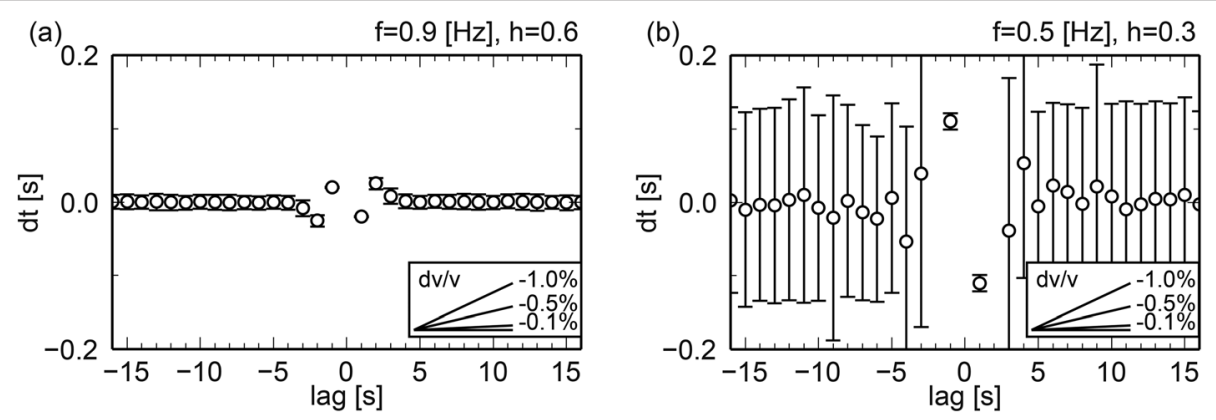

Fig. 11 Apparent time delay of ACFs. Time delays between the reference ACF of the simulated Hi-net waveform with parameters $f=1.0 \mathrm{~Hz}$ and $h=0.7$ and ACFs of simulated waveforms with parameters $\mathbf{a} f=0.9 \mathrm{~Hz}$ and $h=0.6$ and $\mathbf{b} f=0.5 \mathrm{~Hz}$ and $h=0.3$ 
earthquake. This supports the conclusion that the $0.5 \%$ decrease in the velocity at the N.KMIH station after the 2011 Tohoku-Oki earthquake was not due to artificial error caused by the large ground shaking.

\section{Competing interests}

The authors declare that they have no competing interests.

\section{Authors' contributions}

TU analyzed data and drafted the manuscript. TS offered numerous comments about the analysis. KS offered numerous comments about the Hi-net record. YH observed and provided the seismic records of Hi-net. All authors read and approved the final manuscript.

\section{Acknowledgements}

We thank K. Nomura for his helpful comments about the Hi-net records and the sensor. M. Yamamoto suggested the damage of Hi-net sensors by large ground shaking. We also thank two anonymous reviewers for useful comments. We used the Generic Mapping Tools (GMT) (Wessel and Smith 1998) to make the figures in this paper.

\section{Author details}

${ }^{1}$ National Research Institute for Earth Science and Disaster Prevention, 3-1 Tennodai, Tsukuba-shi, Ibaraki 305-0006, Japan. ${ }^{2}$ Association for the Development of Earthquake Prediction, 1-5-18 Sarugaku-cho, Chiyoda-ku, Tokyo 101-0064, Japan.

Received: 30 April 2015 Accepted: 11 August 2015

Published online: 25 August 2015

\section{References}

Brenguier F, Campillo M, Hadziioannou C, Shapiro NM, Nadeau R, Larose E (2008a) Postseismic relaxation along the San Andreas fault at Parkfield from continuous seismological observations. Science 321(5895):1478-1481. doi:10.1126/science.1160943

Brenguier F, Campillo M, Takeda T, Aoki Y, Shapiro NM, Briand X, Emoto K, Miyake H (2014) Mapping pressurized volcanic fluids from induced crustal seismic velocity drops. Science 345(6192):80-82. doi:10.1126/science.1254073

Brenguier F, Shapiro NM, Campillo M, Ferrazzini V, Duputel Z, Coutant O, Nercession A (2008b) Towards forecasting volcanic eruptions using seismic noise. Nat Geosci 1:126-130. doi:10.1038/ngeo104

Maeda T, Obara K, Furumura T, Saito T (2011) Interference of long-period seismic wavefield observed by the dense Hi-net array in Japan. J Geophys Res 116:B10303. doi:10.1029/2011JB008464

Matsubara M, Obara K, Kasahara K (2009) High-VPNS zone accompanying non-volcanic tremors and slow-slip events beneath southwestern Japan. Tectonophysics 472:6-17

Minato S, Tsuji T, Ohmi S, Matsuoka T (2012) Monitoring seismic velocity change caused by the 2011 Tohoku-oki earthquake using ambient noise records. Geophys Res Lett 39:L09309. doi:10.1029/2012GL051405

Nakata N, Snieder R (2011) Near-surface weakening in Japan after the 2011 Tohoku-Oki earthquake. Geophys Res Lett 38:L17302. doi:10.1029/2011 GL048800

Obara K (2002) Nonvolcanic deep tremor associated with subduction in southwest Japan. Science 296:1679-1681. doi:10.1126/science.1070378

Obara K, Kasahara K, Hori S, Okada Y (2005) A densely distributed high-sensitivity seismograph network in Japan: Hi-net by National Research Institute for Earth Science and Disaster Prevention. Rev Sci Instrum 76:021301. doi:10.1063/1.1854197

Ohmi S, Hirahara K, Wada H, Ito K (2008) Temporal variations of crustal structure in the source region of the 2007 Noto Hanto earthquake, central Japan, with passive image interferometry. Earth Planets Space 60(10):1069-1074

Okada Y, Kasahara K, Hori S, Obara K, Sekiguchi S, Fujiwara H, Yamamoto A (2004) Recent progress of seismic observation networks in Japan: Hi-net, F-net, K-NET and KiK-net. Earth Planets Space 56:xv-xxviii

Sens-Schönfelder C, Wegler U (2006) Passive image interferometry and seasonal variations of seismic velocities at Merapi Volcano, Indonesia. Geophys Res Lett 33, L21302. doi:10.1029/2006GL027797

Shiomi K (2013) New measurements of sensor orientation at NIED Hi-net stations. Report NIED 80:1-20 (in Japanese with English abstract)
Shiomi K, Obara K, Kasahara K (2005) Amplitude saturation of the NIED Hi-net waveforms and simple criteria for recognition. Zishin 57:451-461 (in Japanese)

Shiomi K, Sato H, Obara K, Ohtake M (2004) Configuration of subducting Philippine Sea plate beneath southwest Japan revealed from receiver function analysis based on the multivariate autoregressive model. J Geophys Res 109:B04308. doi:10.1029/2003JB002774

Suzuki W, Aoi S, Sekiguchi H, Kunugi T (2011) Rupture process of the 2011 Tohoku-Oki mega-thrust earthquake (M9.0) inverted from strong-motion data. Geophys Res Lett 38:L00G16. doi:10.1029/2011GL049136

Takahashi T, Sato H, Nishimura T, Obara K (2009) Tomographic inversion of the peak delay times to reveal random velocity fluctuations in the lithosphere: method and application to northeastern Japan. Geophys J Int 178(3):1437-1455. do::10.1111/j.1365-246X.2009.04227.x

Takano T, Nishimura T, Nakahara H, Ohta Y, Tanaka S (2014) Seismic velocity changes caused by the Earth tide: ambient noise correlation analyses of small-array data. Geophys Res Lett 41:6131-6136. doi:10.1002/2014GL060690

Ueno T, Saito T, Shiomi K, Enescu B, Hirose H, Obara K (2012) Fractional seismic velocity change related to magma intrusions during earthquake swarms in the eastern Izu peninsula, central Japan. J Geophys Res 117:B12305. do: $10.1029 / 2012 J B 009580$

Ueno T, Shibutani T, Ito K (2008) Configuration of the continental Moho and Philippine Sea slab in Southwest Japan derived from receiver function analysis: relation to subcrustal earthquakes. Bull Seism Soc Am 98(5):2416-2427. doi:10.1785/0120080016

Wegler U, Nakahara H, Sens-Schönfelder C, Korn M, Shiomi K (2009) Sudden drop of seismic velocity after the 2004 Mw6.6 mid-Niigata earthquake, Japan, observed with passive image interferometry. J Geophys Res 114:B06305. doi:10.1029/2008JB005869

Wegler U, Sens-Schönfelder C (2007) Fault zone monitoring with passive image interferometry. Geophys J Int 168:1029-1033. doi:10.1111/j.1365-246X.2006.03284x

Wessel P, Smith WHF (1998) New, improved version of Generic Mapping Tools released. EOS Trans AGU 79(47):579

Yukutake Y, Takeda T, Obara K (2008) Well-resolved hypocenter distribution using the double-difference relocation method in the region of the 2007 Chuetsu-oki Earthquake. Earth Planets Space 60(9):981-985

\section{Submit your manuscript to a SpringerOpen ${ }^{\circ}$ journal and benefit from:}

- Convenient online submission

- Rigorous peer review

- Immediate publication on acceptance

- Open access: articles freely available online

- High visibility within the field

- Retaining the copyright to your article

Submit your next manuscript at $\boldsymbol{\wedge}$ springeropen.com 